Olgu Sunumu/Case Report

\title{
İntakt ventriküler septumun eşlik ettiği pulmoner atrezi
}

Pulmonary atresia with intact ventricular septum

Miğraci Tosun*a, Burcu Torumtay Alıç $a$, Erdal Malatyalıŏ̆lu $a$, Mehmet Çetinkaya $^{a}$, Arif Kökçü $a^{a}$, Tayfun Alper $a$, Gönül Oğur $b$

a Ondokuz Mayıs Üniversitesi, Tıp Fakültesi, Kadın Hastalıkları ve Doğum Anabilim Dalı, Samsun

${ }^{b}$ Ondokuz Mayıs Üniversitesi, Tıp Fakültesi, Çocuk Să̆lı̆̆ı ve Hastalıkları Anabilim Dalı, Samsun

\begin{tabular}{|c|c|}
\hline MAKALE BİLGILLERI & ÖZET \\
\hline Makale Geçmişi: & İntakt ventriküler septumun eşlik ettiği pulmoner atrezi nadir görülen kardiyak bir malfor- \\
\hline $06 / 02 / 08$ & masyondur. 10.000 canlı doğumda 0,58 oranında görülür. Ağır sağ kalp hipoplazisi olan \\
\hline $08 / 09 / 08$ & $\begin{array}{l}\text { vakalarının çoğunda prognoz kötü olduğundan erken tanı konması önemlidir. } \\
\text { J. Exp. Clin. Med., 2009; 26:199-201 }\end{array}$ \\
\hline
\end{tabular}

* Yazışma Adresi:

Miğraci Tosun

Ondokuz Mayıs Üniversitesi,

Tıp Fakültesi,

Kadın Hastalıkları ve Doğum A.D.

Kurupelit, Samsun

e-posta : mirtosun@omu.edu.tr

\begin{abstract}
Pulmonary atresia with intact ventricular septum is a rare cardiac malformation which is present at live birth of 0.58 per 10,000. Because of the prognosis is poor in most severe right heart hypoplasia cases, early diagnosis is critical.

J. Exp. Clin. Med., 2009; 26:199-201
\end{abstract}

\section{Anahtar Kelimeler: \\ Pulmoner Atrezi \\ İntakt Ventriküler Septum \\ Hipoplastik Sağ Kalp}

\section{Key Words:}

Pulmonary Atresia

İntact Ventricular Septum

Hypoplastic Right Heart

C) 2009 OMÜ Tüm Hakları Saklıdır.

\section{Giriş}

Konjenital kalp anomalileri perinatal mortalitenin önde gelen nedenlerinden biridir. Canlı doğumların \%0,6' S1 ve ölü doğumların \% 10' unda konjenital kalp anomalilerine rastlanmaktadır (Fröber ve ark., 2001).

Ultrasonografi ile fetal kardiyak inceleme değerlidir. Günümüzde yüksek rezolüsyonlu B-scan, M-mod ve Doppler ultrasonografi kullanılarak yapılan kalbin kesitsel incelemesi sayesinde antenatal dönemde pek çok fetal kardiyak anomali saptanabilmektedir (Fröber ve ark., 2001).
$\mathrm{Bu}$ çalışmada ultrasonografik olarak ikinci trimesterde tespit edilen ventriküler septumun intakt olduğu pulmoner atrezi ve hipoplastik sağ kalp olgusu sunulmuştur.

\section{Olgu Sunumu}

21 yaşında, gravida 3, parite 1, abortus 1 , yaşayan çocuğu 1 olan anne adayı, gebeliğinin 24. haftasında diş merkezde yapılan ultrasonografisinde, kardiyak anomaliden şüphelenilmesi üzerine kliniğimize sevk edildi. Özgeçmişinde özelliği olmayan gebenin ilaç kullanımı ve eşiyle akrabalık öyküsü yoktu. Soygeçmişinde ise abla- 
sinda triküspit yetmezliği, atrial septal defekt, sağ atrium ve ventrikülde dilatasyon olduğu öğrenildi.

Son adet tarihine göre 24 hafta 1 gün gebeliği olan hastanın fetal biyometrik ölçümleri 23 hafta 4 gün ile uyumluydu.

Kalbin dört kadran görüntüsünde normal dış1 görünüm dikkati çekti. Oldukça küçük görünen sağ ventriküler kavitenin hipertrofik miyokardium ile çevrelendiği, interventriküler septumun intakt olduğu izlendi (Şek. 1). Atrioventriküler kapaklar normal yerleşim bölgelerindeydi. Fakat triküspit kapak mitral kapak ile kıyaslandığında hipoplastik görünüme sahipti. Sol ventrikül çıkışı aort ilişkisi normal olmasına rağmen sağ ventrikül çıkışı ve pulmoner arterler izlenmedi. Kalbin üç damar kesitinde aort ve vena cava superior izlenirken pulmoner arter izlenmedi (Şek. 2). Kalp dişı sistemlerin incelemesinde patoloji saptanmad1. Amniosentez sonrası fetal karyotip 46, XY olarak belirlendi. Di-George Sendromu açısından Fish yöntemi ile araştırılan fetusta 22 q delesyonu bulunmadi.

Aileye tespit edilen kardiyak patoloji ve prognoz hakkında bilgi verilip, onayları alındıktan sonra gebeliğin sonlandırılmasına karar verildi. Misoprostol ile doğum indüksiyonu uygulanarak 0 apgarl1 710 gram erkek fetus doğurtuldu. Postpartum kardiyak otopsi bulguları sağ ventrikül duvar kalınlığ $0,3 \mathrm{~cm}$, sol ventrikül duvar kalınlığ $0,5 \mathrm{~cm}$, sağ ventrikül lümen genişliği $0,4 \mathrm{~cm}$, sol ventrikül

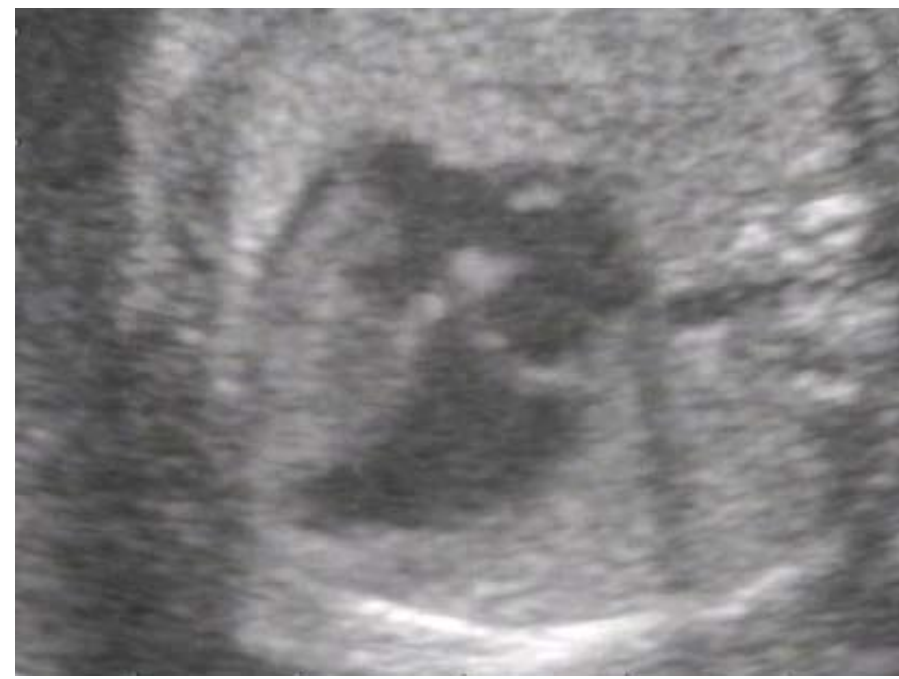

Şek. 1. Hipoplastik sağ ventrikül görüntüsü

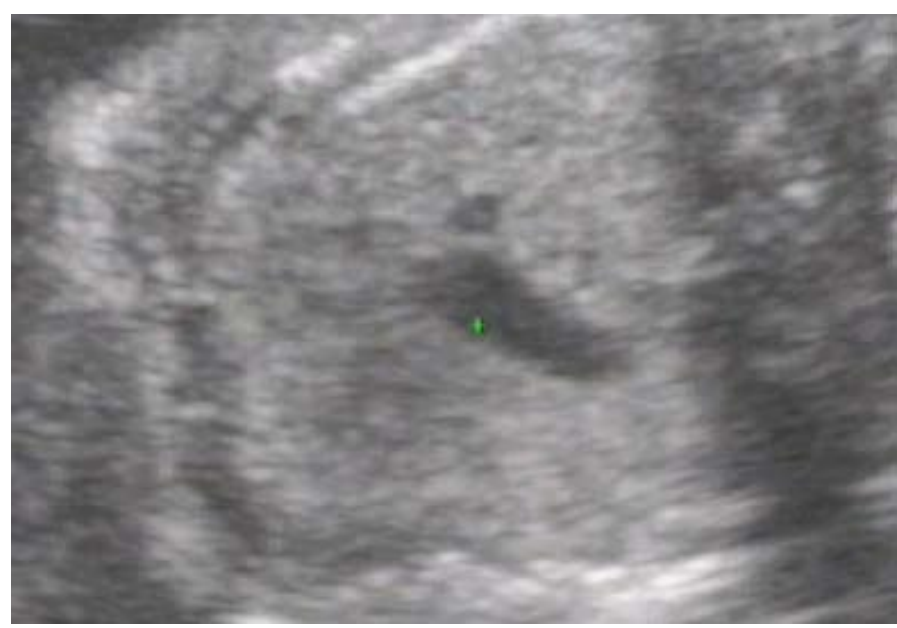

Şek. 2. Pulmoner arterin izlenmediği fetal kalbin üç damar kesiti. lümen genişliği $1 \mathrm{~cm}$ idi. Sağ ventrikül hipoplazik olarak değerlendirildi.

\section{Tartışma}

İntakt ventriküler septumun eşlik ettiği pulmoner atrezi nadir bir anomali olup yapisal kalp defektlerinin \%1,7'ni oluşturur (Fröber ve ark., 2006). Pulmoner arter, genellikle küçük ve 2-3 mm çapındadır. Değişen derecelerde sağ ventrikül ve triküspit hipoplazisi olaya katılır. Bazı olgularda sağ ventrikül hipoplazisi yerine sağ ventrikülde dilatasyon ve triküspit yetmezliği olabilir. Çoğu vakada gelişmemiş sağ ventrikül varken $(\% 80)$ normal veya genişlemiş sağ ventrikül (\%6,5 ve \%13) daha nadirdir (Freedom ve ark., 1978). Sağ ventrikül ile koroner arterler arasında ilişki sık görülen bir bulgudur. Kör sonlanan ventrikül için bu bir çıkış noktasıdır (Todros ve ark., 2003). Duktus arteriozus daima açıktır ve sıklıkla normal görünümdedir.

Kalbin dört kadran görüntüsünde hipoplazik sağ ventrikül izlenmesi, pulmoner atrezi ön tanısını düşündürmelidir (Makato ve ark., 1999). Olgunun kliniğimize gönderilme nedeni, fetal kalbin dört kadran görüntüsünde sağ ventrikülün izlenememiş olmasıydı. Yine kalp tabanının üst kesitinden elde edilen üç damar görüntüsünde vena kava superior ve aort izlenirken pulmoner arterin izlenmemesi tanıya yardımcidır. Bu bulgu da olgumuzda mevcuttu. Renkli Doppler ultrasonografi, sağ ventrikülden ileriye pulmoner artere akım olmadığının ve duktus arteriozus ile pulmoner arter arasında ters akım olduğunun gösterilmesi açısından değerlidir. Erken gebelik döneminde tanıda en önemli ipucu sağ ventrikül kontraktilitesinde azalmanın izlenmesi olabilir (Berning ve ark., 1996)

Erken tanı alan vakalarda, prognoz tahmini amacıyla yapılan çalışmalarda, ileri derecede sağ ventrikül dilatasyonu ve hipertrofik sağ ventrikül duvarı olumsuz prognozla ilişkili bulunmuştur (Todros ve ark., 2003). Bizim vakamızda sağ ventrikül duvarı hipertrofik ve sağ ventrikül hipoplazik olarak izlendi. Bazı vakalarda triküspit yetmezliği sağ atriumda dilatasyona, dilate atrium da akciğer hipoplazisine neden olabilir (Hornberger ve ark., 1994). Bu durum prognozun kötüleşmesinde önemli role sahiptir.

Aileye fetal karyotipleme önerilmelidir. İzole intakt ventriküler septumun eşlik ettiği pulmoner atrezi olgularında anöploidi riski düşüktür. Anöploidi sıklığ $1 \% 2,3$ ile \%5 arasında bildirilmiştir (Daubeney ve ark., 1998). Olgumuzun karyotip incelemesi normaldi. Gebeliği termine etme oranları, tanının 24. gebelik haftasından önce koyulduğu olgu serilerinde yüksek olmuştur. Farklı çalışmalarda terminasyon oranları \%82 (Daubeney ve ark., 1998) ve \% 100 (Maeno ve ark., 1999) olarak belirtilmiştir.

Gebeliğin devamına karar verilen olgularda tirküspit yetmezliği, kardiomegali ve hidrops gelişimi açısından fetus takip edilmelidir. Literatürde 28. gebelik haftasında kalp yetmezliği gelişen bir fetusa intrauterin pulmoner kapağa valvulutomi yapılıp başarılı olunan bir olgu sunulmuştur (Arzt ve ark., 2003). Hidrops gelişmeyen olgular 
miadında, kontrendikasyon yoksa vajinal doğurtulabilir. $\mathrm{Bu}$ bebeklerin doğduklarında duktus arteriosus bağımlısı olacakları unutulmamalıdır.

\section{Sonuç}

Günümüzde aileler her yönden sağllklı bir bebek arzu etmektedirler. Ultrasonografiye bir tarama yöntemi olarak değil tanı yöntemi olarak bakmakta ve takiplerini yapan hekimler üzerinde yoğun baskı kurmaktadırlar. Ülkemizde gelinen ultrasonografi bilgi birikimi, rutin fetal ekokardiografi için uygun olmasa da dört kadran ve üç damar görüntüsü gibi kolay öğrenilebilir kalp inceleme kesitlerinin rutin fetal ultrasonografiye eklenmesiyle bazı kardiak anomalilerin intrauterin tanınması mümkün olabilir.

\section{KAYNAKLAR}

Arzt, W., Tulzer, G., Aigner, M., Mair, R., Hafner, E., 2003. Invasive intrauterine treatment of pulmonary atresia/intact ventricular septum with heart failure. Ultrasound Obstet. Gynecol. 21, 186-188.

Berning, R.A., Silverman, N.H., Villegas, M., Sahn, D.J., Martin, G.R., Rice, M.J., 1996. Reversed shunting across the ductus arterio-sus or atrial septum in utero heralds severe congenital heart disease. Coll. Cardiol. 27, 481-486.

Daubeney, P.E., Sharland, G.K, Cook, A.C., Keeton, B.R., Anderson, R.H., Webber, S.A., 1998. UK and Eire collaborative study of pulmonary atresia with intact ventricular septum. Pulmonary atresia with intact ventricular septum. Impact of fetal echocardiography on incidence at birth and postnatal outcome. Circulation. 98, 562-566.

Freedom, R.N., Dische, M.R, Rowe, R.D., 1978. The tricuspid valve in pulmonary atresia and intact ventricular septum: A morphological study of 60 cases. Arch. Pathol. Lab. Med. 102, 28-31.

Fröber, R., Kohoutek, T., Kähler, C., Beensen, V., Hauschild, R., Schulze, E., Linss, W., 2001. Pulmonary atresia with hypoplastic right ventricle. A Clinical Embriyological Study. Fetal Diagnosis and Therapy. 16, 274-279.

Fröber, R., Kohoutek, T., Kähler, C.H., 2006. Echocardiographic Predictors of Outcome in Fetuses with Pulmonary Atresia with Intact Ventricular Septum. J. Am. Society Echocardiog. 19, 1393-1400.

Hornberger, L.K., Benacerraf, B.R., Bromley, B.S., Spevak, P.J., Sanders, S.P., 1994. Prenatal detection of severe right ventricular outflow tract obstruction pulmonary stenosis and pulmonary atresia. Ultrasound Med. 13, 743-750.

Makato, N., Yoshı, M., Masoto, K., 1999. Echocardiographic findings of pulmonary atresia or critical pulmonary stenosis and intact ventricular septum in utero. Pediatr. Int. 41, 716-721.

Maeno, Y.V., Boutin, C., Hornberger, L.K, McCrindle, B.W., Cavallé-Garrido, T., Gladman, G., Smallhorn, J.F., 1999. Prenatal diagnosis of right ventricular outflow tract obstruction with intact ventricular septum, and detection of ventriculocoronary connections. Heart. 81, 661-668.

Todros, T., Paladini, D., Chiappa, E., Russo, M.G., Gaglioti, P., Pacileo, G., Cau, M.A., Martinelli, P., 2003. Pulmonary stenosis and atresia with intact ventricular septum during prenatal life.Ultrasound Obstet. Gynecol. 21, 228-233. 